\title{
Educação Especial com a Educação Física
}

\author{
ACOSTA, Gerson Falcão ${ }^{[1]}$
}

ACOSTA, Gerson Falcão. Educação Especial com a Educação Física. Revista Científica Multidisciplinar Núcleo do Conhecimento. Ano 03, Ed. 05, Vol. 05, pp. 32-41, Maio de 2018. ISSN:2448-0959

\section{RESUMO}

O artigo vem elencar a importância da educação especial dentro da Educação Física. O papel da escola é incluir o aluno deficiente no ambiente escolar e transformar este momento educativo num momento prazeroso com relações interpessoais trabalhando respeito e solidariedade. E o papel do docente é garantir essa inclusão significativa. Identificando as dificuldades encontradas no ambiente escolar para a inclusão, apontando alguns obstáculos como a acessibilidade de que precisam ser resolvidos para a inclusão no ambiente escolar e conhecer quais ações possibilita a inclusão de crianças com necessidades especiais no cotidiano escolar. E o papel do educador físico é trazer esse aluno deficiente adaptando para seu universo dentro das aulas práticas.

Palavras-chave: Deficiente, Acessibilidade, Escolar, Inclusão.

\section{INTRODUÇÃO}

A legislação é um importante instrumento para garantir o direito dos deficientes, e também auxiliam na luta contra a discriminação nos quais educandos especiais incluídos na escola de forma natural sendo respeitados e aceitos pelos demais alunos. Sendo assim, algumas atividades lúdicas contribuíram muito, para que ocorra esse processo. Logo, esse estudo mostrará que a atividade lúdica e a oportunidade de inserir este portador em jogos e brincadeiras ou até mesmo na socialização em sala de aula dentro da aula de educação física.

Esta pesquisa tem como base o que esta definido na Lei de Diretrizes e Bases da Educação Nacional (LDBEN), de 20 de dezembro de 1996, sobre os aspectos que norteiam como os educando com necessidades especiais devem ser incluídos em classes regulares de ensino. Quanto à questão da ludicidade, autores como Johan Huizinga (1971), Chateau (1987) e Nhary (2006) trouxeram grande contribuição ao trabalho. 
Em algumas instituições de ensino não possuem estrutura adequada, além disso, poucos profissionais da área da educação física estão preparados para conviver com esse novo momento da educação brasileira, faz-se necessário que haja um conhecimento sobre as práticas pedagógicas dentro da prática de educação física adequada que possibilitará a nova realidade à educação especial.

Os objetivos mostram as dificuldades encontradas no ambiente escolar e para o docente e para a inclusão, apontando alguns problemas que precisam ser solucionados para a inclusão escolar e conhecer ações que possibilitam as crianças deficientes no cotidiano escolar.

As ações utilizadas neste trabalho é uma prática do dia a dia, com observações, e pesquisa bibliográfica. Através deste estudo foi possível identificar, avaliar e conhecer a importância da inclusão escolar para a sociedade e principalmente para os deficientes com as contribuições de adaptações feitas pelo professor de educação física.

A inclusão escolar faz com que todos os alunos participam das ações escolares nas quais possam ser limitados em seu direito de participar diariamente do planejamento escolar e principalmente da aula da aula de educação física, segundo suas capacidades, e sem que nenhuma delas possa ser motivo para uma diferenciação que os excluirá das suas turmas.

Existem algumas situações que nos leva a questionar se é necessário compreender os processos de inclusão escolar, como esta nas leis e que minorias das classes sociais estejam excluídas, contra este processo.

Os educadores físicos precisam contribuir para instituição da escola como espaço de aprendizagem para todos os alunos, problematizando o currículo escolar, os processos de avaliação, os momentos de formação, planejamento, as relações estabelecidas nesse cotidiano, os apoios que necessitamos para dar conta de todos os alunos, as parcerias necessárias, bem como as políticas públicas favorecedoras da garantia de acesso, permanência e ensino com qualidade a todos os alunos.

O que se busca com isso, é aumentar a qualidade de ensino aos educandos, nas a instituição com políticas públicas educacionais que precisam reconhecer que as contribuições daqueles que vivenciam esta realidade traz questões trazidas pelos educandos para o contexto da sala de aula, ou seja, os educadores.

\section{A INCLUSÃO}

A inclusão escolar impõe uma escola participativa em que todos os alunos que estão inseridos com ou sem dificuldades tenham condições e acesso pelas quais possam ser valorizados em seu direito de participar ativamente do processo escolar, segundo suas capacidades, e sem que nenhuma delas possa ser motivo para uma diferenciação que os excluirá das suas turmas.

Esta situação nos leva a argumentar que se faz necessário compreender os processos de inclusão escolar, como frutos das lutas articuladas pelas minorias sociais excluídas, contra um processo de exclusão.

Assim, como educadores, precisamos contribuir para instituição da escola como espaço de aprendizagem para todos os alunos, problematizando o currículo escolar, os processos de avaliação, os momentos de formação, planejamento, as relações estabelecidas nesse cotidiano, os apoios que necessitamos para dar 
conta de todos os alunos, as parcerias necessárias, bem como as políticas públicas favorecedoras da garantia de acesso, permanência e ensino com qualidade a todos os alunos.

\section{RECURSOS}

$\mathrm{Na}$ visão de Ferreira as promoções da Educação Inclusiva existem novos recursos e novos olhares sobre os trabalhos existentes, sendo necessário desenvolver. Mas, o professor com todo o conjunto de competências e experiências que tem é certamente o principal recurso em que a Educação Inclusiva se pode apoiar (FERREIRA, 2006).

Para promover e fazer acontecer a Educação Inclusiva muitas vezes a de encontrarmos mais pessoas com perfis profissionais diferentes, ou encontrar novos recursos diferentes é também meio de estratégias reflexivas, de um trabalho cooperativo lançando um novo olhar sobre as práticas docentes, sobre a equipe e os recursos que a escola dispõe.

Precisamos de professores de educação físicas comprometidos e que vivam práticas e teorias habituais de formação e ainda, conhecer e desenvolver de um aluno deficiente com as práticas que permita ao mesmo alcançar o sucesso, isto é, atingirem o limite superior das suas capacidades.

\section{A EDUCAÇÃO ESPECIAL}

Gonçalves (2005) cita que no Brasil há 24 milhões de pessoas que apresentam algum tipo de deficiência e que isso deve ser tratado como uma questão social de interesse de todos. Nos diversos períodos da história da humanidade, a deficiência era vista de diferentes maneiras. Existiu várias interpretações para a deficiência.

Segundo Cavalcante (2005) na maior parte das escolas brasileiras a inclusão das crianças portadoras de necessidades educativas especiais não acontece da maneira que deveria realmente acontecer. A referida autora cita que talvez por falta de informação ou até mesmo pela omissão de muitos pais, dos educadores e do poder público, muitas são as crianças que ainda vivem isoladas em instituições especializadas, privadas de convier com as demais crianças em uma escola regular.

A partir da convivência das crianças deficientes dentro de uma escola regular, haverá muitas possibilidades de desenvolverem plenamente as suas potencialidades, além de quê, as demais crianças aprenderão a conviver com um colega que necessita de seu apoio e da sua compreensão. Haverá nisso uma troca que favorecerá o aprendizado de todos. Como cita:

O motivo principal de elas estarem na escola é que lá vão encontrar um espaço genuinamente democrático, onde partilham o conhecimento e a experiência com o diferente, tenha ele a estatura, a cor, os cabelos, o corpo e o pensamento que tiver. Por isso quem vive a inclusão sabe que está participando de algo revolucionário. (CAVALCANTE, 2005, p. 40).

O importante é que o professor de educação física saiba como se dá o uso desse material, que seja capacitado para este fim. Algumas orientações que devem ser passadas para o aluno no que diz respeito à locomoção, comunicação e acessibilidade. É necessário, por exemplo, colocar cercados no chão, abaixo dos extintores de incêndio e também deve ser instalados corrimões nas escadas, caso existam escadas na 
escola.

A educação inclusiva acolhe todas as pessoas, sem exceção. É para o estudante com deficiência física, para os que têm comprometimento mental, para os superdotados, para todas as minorias e para a criança que é discriminada por qualquer outro motivo.

O espaço escolar deve ser organizado de modo a tornar a educação acessível a todos os alunos. A LDB $\mathrm{n}^{\circ}$ 9394/96 tem um capítulo destinado à Educação Especial e, em seu artigo 58 diz que a Educação Especial é uma modalidade destinada aos portadores de necessidades educativas especiais e que deve ser ofertada, de preferência na escola regular e, se necessário, os serviços especializados atuarão juntamente com a escolar regular em que o aluno está matriculado.

\section{A INCLUSÃO DE ALUNOS PNEs (PORTADORES DE NECESSIDADES ESPECIAIS) NAS AULAS DE EDUCAÇÃO FÍSICA}

Nas aulas de educação física de acordo com Bracht (1992, p. 36), ao mesmo tempo em que qualificam, são ricas em considerar as preferências da maioria elitizada em habilidades esportivas, através da seleção dos melhores atletas representantes do "esporte na escola", e não em defesa do "esporte da escola", reforçando a apatia e o desânimo dos menos expressivos, sempre discriminados e, muitas vezes, levados a ceder seu lugar na quadra, tendo-se em vista sua falta de domínio das habilidades esportivas e gerando desafios a serem solucionados.

Estes trabalhos propõem ao educador físico a apresentar formas para incluir o aluno deficiente nas aulas de educação física, buscando abordar a questão de atividades propostas pela Educação Física com o objetivo de inclusão dos deficientes físicos segundo suas individualidades e limitações e tendo como incentivo o fato de ser a educação um direito de todos. A educação física com a prática esportiva tem uma importância grande para o desenvolvimento dos indivíduos, direcionando-se ao entendimento de todo o desenvolvimento do deficiente que tem dificuldades na área motora, visando à saúde, o lazer e a socialização do educando, de forma a lhe proporcionar uma vida normal, e com um grau maior de desempenho nas suas atividades diárias e melhor qualidade de vida.

\section{ACOMPANHAMENTO}

Aprendemos a todo o momento, que o aluno deficiente deve participar dos jogos e competição oferecidos pela escola com o treinamento do professor de educação física e existem mudanças, no tempo e no espaço vivido. A palavra aprender exprime: transformar toda a ação possível em ação introjetada e refletida, bem como, toda oportunidade de crescimento e desenvolvimento, em ação construída. Cada momento de aprendizagem representa a possibilidade de aprender o sentido e o significado do crescimento.

O nesse processo ensino e aprendizagem, transformar e neste caso o jogo construído para os alunos fará com que os alunos competem no saber mais. À aprendizagem mobiliza um processo pelo qual gera uma energia a partir de experiências guardadas. Ensinar através de o jogo mostrar a capacidade do aluno permitindo a competição. De acordo com Fialho (2007, p. 129).

A intensidade do jogo é tão grande que a fascinação que ele exerce sobre as pessoas é imensurável. Com isso, acreditamos que a utilização de jogos na educação vem ao encontro de uma opção diferenciada, 
capaz de atuar como reforço de conteúdos, que por sua vez podem ser aliados ou não pelo professor e, também como instrumento interessante e motivador no ensino-aprendizagem. Porém, é valido relembrarmos que esses jogos são de apoio e que, para realizá-los, o aluno deve ter já o conhecimento do assunto.

\section{A POSTURA DO PROFESSOR DE EDUCAÇÃO FÍSICA PARA MORIN E PAULO FREIRE}

Para Morin muito conhecimento traz enganos, pois gera certezas que pode separar e dividir, pois freire concorda com a ideia, ou seja, um professor seja ele de educação física ou não, não sabe tudo e muito menos de um aluno deficiente, pois necessita de um estudo diário buscando conhecer o aluno e o seu ambiente. O professor tem postura de estar pesquisando e trabalhando em sua prática, mas isso não deixa de proceder com os anos de docência pelo contrario ser professor dependemos de um estudos continuo.

Morin ainda diz que o conhecimento pertinente que torna todos mais humanos, ou seja, confirmar essas teorias é ao mesmo tempo ter convergências de pensamentos entre ambos, pois a partir desses autores se buscam contribuições que ajuda na vida inicial de professores. Além de analisar as especificidades do trabalho de acordo com o currículo demostrando a relação entre docente e discente e o seu conhecimento através das práticas de sala de aula refletindo sobre suas necessidades dentro de suas aulas. Seve se discutir a didática de um professor iniciante, pois dai começa a formação de sua identidade.

Para conhecer os pensamentos destes autores foram realizadas várias leituras e releituras de suas obras. O objetivo deste artigo foi mostrar a convergência de opiniões dos os atores, isto é, quais ideias são contrárias entre Freire e Morin, contemplando também as reflexões dos mesmos.

De acordo com os autores os professores nos seus primeiros anos de formação deveriam ter acesso a práticas dialógicas e reflexivas que desvelem as suas concepções ingênuas e lhes permitam o confronto criativo tanto com experiências quanto com perspectivas teóricas importantes para a sua formação crítica.

Convergências de pensamento entre Paulo Freire e Edgar Morin podem ser encontradas na integra nas obras "Pedagogia da Autonomia: Saberes Necessários à Prática Educativa" de Paulo Freire e "Os Sete Saberes Necessários à Educação do Futuro" de Edgar Morin que nos permitem uma primeira aproximação às convergências do pensamento educacional destes autores.

Considerando que existe a necessidade de uma prática reflexiva do professor, e que a mesma deve começar durante a formação inicial, selecionamos algumas ideias que podem contribuir com o debate e a análise da realidade, essenciais para a formação do profissional docente. Algumas das ideias convergentes e que foram selecionadas para este trabalho são discutidas a continuação. Para ambos os extremismos, ainda para Freire "ensinar exige reconhecer que a educação é ideológica" (FREIRE, 1997, p. 125), e que a ideologia nos torna míope. Morin também comenta a respeito, concordando que "o mito e a ideologia destroem e devoram os fatos" (MORIN, 1999, p. 30).

Segundo ele, as ideias (idealidade, com racionalidade) são o que nos mantêm lúcidos de ideias (idealismo, produto da racionalização). Análogo a isso, Freire nos diz "na verdade, só ideologicamente posso matar as ideologias" (FREIRE, 1997, p. 132).

\section{SUGESTÕES DE ATIVIDADES DENTRO DA POSTURA DO EDUCADOR FÍSICO}


Uma das sugestões de atividades a ser trabalhada com o aluno deficiente e os jogos que vem como alicerce para os professores de Educação Física, isso por que o professor no papel de mediador deve estimular e despertar o interesse nos alunos de diferentes formas, fazendo com que as aulas sejam mais apreciadas e prazerosas aos alunos ao mesmo tempo em que alcança o seu principal objetivo que é educar.

Muito são os estudos em relação à ludicidade para os deficientes nas aulas de Educação Física, existe uma importância que auxilia no desenvolvimento do aprendizado da criança deficiente a cada momento, ajudando no seu desenvolvimento físico, afetivo, intelectual e social, bem como na formação de conceitos e ideias, desenvolvendo a expressão oral e corporal, reforçando habilidades sociais e reduzindo a agressividade.

Do professor vem o compromisso de criar e trazer estas crianças para as atividades, deixando aparente a importância do desenvolvimento das habilidades desses alunos deficientes na construção de um ambiente saudável e natural e um mundo diferente, pois a diversidade existe.

Consideramos que o papel do educador físico é fundamental na finalidade de preparar a criança deficiente para jogar e competir de forma adaptada em sala de aula, transformando o clima da aula em um ambiente cooperador e rico em aprendizado, ou seja, ao brincar a criança deverá saber ganhar e perder, sem perder o respeito pelo adversário, descobrindo assim a aceitação do ganhar e perder, tendo como algo natural ao jogar com os colegas.

O lúdico na Educação Física desenvolve, e propicia o desenvolvimento integral do aluno e neste sentido com uma aprendizagem que auxiliará na formação de indivíduos críticos, pensante e transformadores de uma realidade em que vivem. Por isso, que é muito importante que as escolas e os educadores, incentivem a prática do jogo em sala de aula, para conduzir as aulas prazerosas do aprendente.

É extremamente significativo para a criança poder conhecer, compreender e construir seus conhecimentos, ou seja, tornarem-se cidadãos autônomos capazes de pensar por conta própria, sabendo resolver problemas e compreendendo um mundo que exige diferentes conhecimentos e habilidades.

Freire busca o suporte teórico necessário para sua proposta em Piaget, que, sem dúvida, apresenta muitas contribuições no que diz respeito ao desenvolvimento infantil, principalmente do ponto de vista da cognição. Mas, vale destacar que, ao introduzir os conhecimentos dessa teoria e procurar estabelecer relações com uma proposta para a educação física, o autor deveria ter claro que seria preciso enfrentar uma questão fundamental: o fato de que Piaget ao considerar a relevância das ações corporais, o faz enquanto estas influenciam no desenvolvimento cognitivo.

\section{CONSIDERAÇÕES FINAIS}

O fato é que algumas instituições de ensino não possuem estrutura adequada, além disso, poucos profissionais da área da educação estão preparados para viver esse novo momento da educação brasileira, faz-se necessário que haja a quebra dos paradigmas e obter o conhecimento sobre as práticas pedagógicas adequadas que possibilitará que esta nova realidade seja de fato efetivada. 
Os objetivos aqui apresentados são identificar as dificuldades encontradas no ambiente escolar para a inclusão, apontar alguns paradigmas que precisam ser quebrados para a inclusão escolar e conhecer quais ações possibilitam a inclusão de crianças com necessidades especiais no cotidiano escolar.

A tipologia utilizada neste trabalho é uma prática Real e de campo, os meios de investigação usados foram visitas acadêmicas, pesquisa bibliográfica e entrevista com perguntas fechados e abertos. Através deste estudo foi possível identificar, avaliar e conhecer a importância da inclusão escolar para a sociedade e principalmente para os portadores de necessidades especiais.

Esse estudo mostra ainda que a sociedade e mesmo as família de portadores de necessidades especiais precisam aceitar e compreender que ser especial não é ser incapaz, mas ser diferente e com capacidades surpreendentes.

As práticas pedagógicas brasileiras supostamente apoiadas no sócio-interacionismo enfatizam fortemente o papel do professor. Frequentemente, as orientações fornecidas ao professor, ao menos aquelas efetivamente praticadas, parecem assumir que a criança nada pode aprender que não seja explicitado e orientado pelo professor, havendo pouco reconhecimento ou preocupação com o que a criança aprende através do que é ensinado e, principalmente, através de suas ações, independentemente de ter recebido instruções para executá-las. Deve-se ressaltar que um dos aspectos essenciais do construtivismo, de qualquer construtivismo, é a proposição de que toda a aprendizagem e todo o conhecimento são governados por processos tácitos e abstratos, que prevalecem sobre o explícito e o concreto (MAHONEY, 1998).

O sócio-interacionismo, especialmente na concepção atribuída a Vygotsky, tem sido processado de uma forma peculiar em alguns meios educacionais. Alguns aspectos da obra de Vygotsky têm tido um impacto significativo no campo da educação.

Entre esses, Van Der Veer e Valsiner (1995) destacam três princípios ou hipóteses: a primeira delas é a proposição Vygotskyana de que os processos cognitivos são construídos num meio histórico-cultural e mediados pelos agentes sociais que interagem com os indivíduos; a segunda, estreitamente ligada à primeira, é que o desenvolvimento da criança difere essencialmente segundo ela frequente ou não a escola, e, finalmente, o terceiro ponto a influenciar a educação atual diz respeito ao papel decisivo da "zona de desenvolvimento proximal", o lugar privilegiado de ação do educador.

Isso cabe ao aluno deficiente de acordo com o trabalho prático do professor de educação física para ter um resultado significativo, pois as atividades lúdicas e os jogos fazem a inserção desse aluno junto aos outros a competir e a aceitação, pois estamos vivendo dentro da diversidade e existe sim aquele que é diferente em etnias ou em deficiências seja ela qual for.

A postura desse professor é de trabalhar com qualquer criança pensando no bem-estar dele e de todos os presentes em sala de aula.

\section{REFERÊNCIAS}

BRASIL, Ministério da Educação e do Desporto. Referencial Curricular para a Educação Infantil. Brasília: MEC/SEF, 1998. 
CARVALHO, R. E. Temas em educação especial. Rio de Janeiro: WVA, 1998.

GLAT, R.; KADLEC V. A criança e suas deficiências: métodos e técnicas de ação psicopedagógica. Rio de Janeiro: Agir, 1995.

BAPTISTA, Cláudio Roberto e ROSA, Cleonice (orgs). Reflexões e projetos de intervenção. Porto Alegre. Artmed, 2002.

BRASIL. Declaração de Salamanca e linha de ação sobre necessidades educativas especiais. 2. Ed. Brasília: CORDE, 1997.

BRASIL, Lei de Diretrizes e Bases da Educação Nacional. Lei n9. 394/96, de 20 de dezembro de 1996.

BRASIL. Secretaria da Educação Fundamental. Parâmetros Curriculares Nacionais: Apresentação dos temas transversais e Ética. Brasília: MEC/SEF, 1997.

CAMARGO, Jr. Walter. Transtornos invasivos do desenvolvimento: $3^{\mathbf{0}}$ milênio. Secretaria Especial dos direitos Humanos, Coordenadoria Nacional para Integração da Pessoa Portadora de Deficiência, Brasília, 2005.

CAVALCANTE, Meire. A escola que é de todas as crianças. IN: Revista Nova Escola. São Paulo: Fundação Victor Civita, no 183, 2005. P.40-45.

FREIRE, Paulo. Pedagogia da Autonomia: saberes necessários à prática educativa. São Paulo: Paz e Terra, 1997.

GUIMARÃES, Arthur. Inclusão que funciona. IN: Revista Nova Escola. São Paulo: Fundação Victor Civita, 2003. P.43-47.

MANTOAN, Maria Teresa Eglér. Inclusão escolar: O que é? Por quê? Como fazer? São Paulo: Moderna, 2003.

MANTOAN, Maria Teresa Eglér. Ensinando a turma toda, Revista pátio, ano v, $\mathrm{n}^{\circ}$ 20, fevereiro/abril 2005.

MORIN, E. Os sete saberes necessários á prática educativa. São Paulo: Cortez, 1999.

KISHIMOTO, Tisuko Morchida. Jogos Infantis: o jogo, a criança e a educação. Petrópolis: RJ: Vozes, 1993. Jogos infantis: O jogo a criança e a educação. 5 ed. Petrópolis,RJ:VOZES,1998.

WISE, Liz. Trabalhando com Hannah: Uma criança especial em uma escola comum. Trad. Ronaldo Cataldo Costa. Porto Alegre: Artmed, 2003.

${ }^{[1]}$ Formado em Educação Física - Especialista em Diversidade e Educação Especial 
Revista Científica Multidisciplinar Núcleo do Conhecimento - RC: 15652 - ISSN: 2448-0959

https://www.nucleodoconhecimento.com.br/educacao-fisica/educacao-especial-com-a-educacao-fisica

\section{PUBLIQUE SEU ARTIGO CIENTÍFICO EM:}

https://www.nucleodoconhecimento.com.br/enviar-artigo-cientifico-para-submissao 